Оригинальная статья/Original article

УДК 663.97.0048

DOI: http://doi.org/10.20914/2310-1202-2016-3-184-188

Перспективы использования вторичных сырьевых ресурсов при

изготовлении табачных изделий

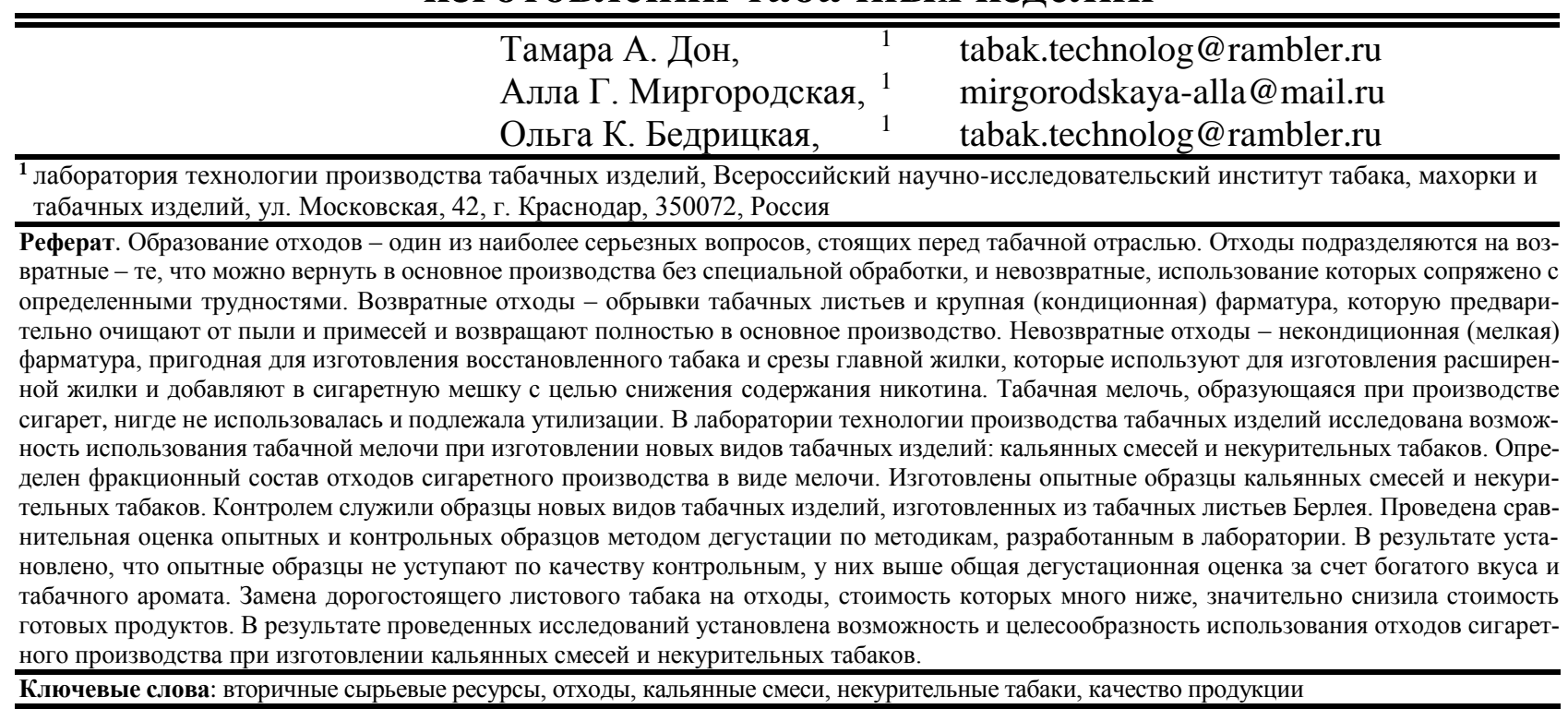

\title{
Recycling of tobacco wastes after tobacco products manufacturing
}

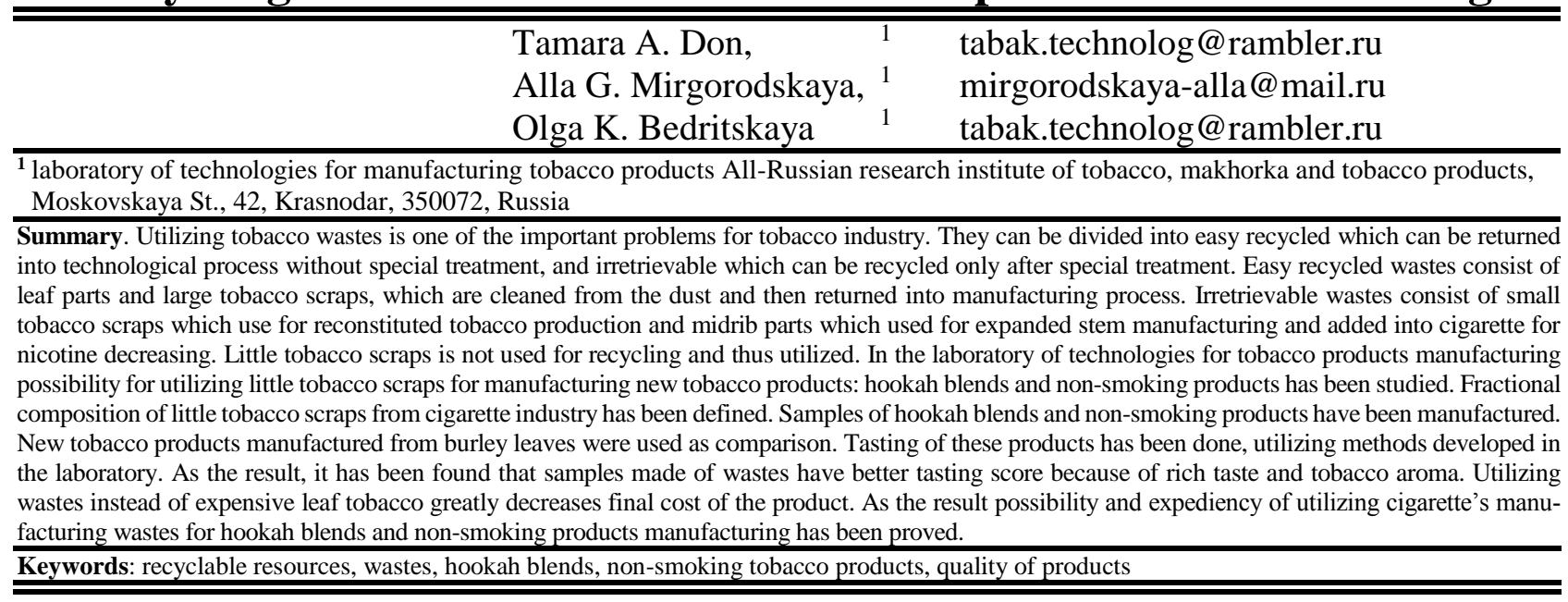
Keywords: recyclable resources, wastes, hookah blends, non-smoking tobacco products, quality of products

\section{Введение}

Технологический процесс производства табачной продукции неизбежно связан с образованием отходов, которые по своим технологическим показателям не могут быть использованы в курительных изделиях. Количество отходов зависит от многих факторов: применяемой технологии, используемого оборудования, свойств сырья и материалов, условий хранения и параметров окружающего воздуха. Ежегодно на табачных фабриках, действующих на территории России, образуется порядка 15000 тонн отходов Для цитирования

Дон Т.А., Миргородская А.Г., Бедрицкая О.К. Перспективы использования вторичных сырьевых ресурсов при изготовлении табачных изделий // Вестник ВГУИТ. 2016. № 3. С. 184-188. doi:10.20914/2310-1202-2016-3-184-188

184 табачного сырья, частично или полностью утратившего технологические свойства [1]. В связи с чем перед отраслью достаточно остро стоят вопросы утилизации или возможности использования их в основном производстве.

Решение этих вопросов можно сформулировать следующим образом:

- разработка методов уменьшения общего количества отходов;

- эффективное вовлечение отходов в хозяйственный оборот.

For citation

Don T.A., Mirgorodskaya A.G., Bedritskaya O.K. Recycling of tobacco wastes after tobacco products manufacturing. Vestnik VSUET [Proceedings of VSUET]. 2016. no. 3. pp. 184-188. (in Russian). doi:10.20914/2310-1202-2016-3-184-188 
Отходы подразделяются на возвратные и невозвратные.

Возвратные отходы - это отходы, которые могут быть возвращены в производство без дополнительной обработки. К ним относят:

- обрывки табачных листьев размером более $20 \mathrm{~cm}^{2}$;

- кондиционную (крупную) фарматуру (обрывки листьев размером менее $20 \mathrm{~cm}^{2}$, не проходящие через сито с пробивными круглыми отверстиями диаметром 5 мм). Эти отходы очищают от пыли, посторонних примесей, и возвращают в основное производство [2];

- волокно после переработки брака сигарет и штранга увлажняется и возвращается в резаный табак.

Невозвратные отходы - это отходы, требующие дополнительной переработки перед использованием, или утилизации.

К ним относят:

- некондиционную фарматуру - более мелкие обрывки листьев, проходящие через сито с отверстиями диаметром 5 мм и состоящие из $50 \%$ табачной мелочи, 20\% черешков и $30 \%$ пыли используют в производстве восстановленного табака;

- срезы главных и боковых жилок табачного листа различной формы, которые отделяются от резаного табака в узлах сепарации сигаретных машин при формировании табачного жгута и используются при производстве расширенной жилки различного состава на предприятиях, специализирующихся на выпуске этой продукции («ГросСтемс» и «КресНево»). Добавление расширенной жилки в сигаретную машину - один из основных способов снижения никотина в табачных изделиях.

- табачная мелочь - мелкая фракция резаного табака, утратившая технологические свойства, образуется на сигаретных машинах.

- пыль - основная часть невозвратных отходов, имеющая в своем составе до $50 \%$ минеральных примесей, образуется на всех этапах технологического процесса производства табака и табачных изделий, собирается в индивидуальных и централизованных пылесборникахциклонах.

И табачная мелочь, и пыль практически нигде не используются и подлежат утилизации путем захоронения на специальных полигонах ТБО (твердые бытовые отходы), приспособленных для размещения бытовых и промышленных отходов 3 и 4 классов опасности. К отходам производства предъявляются более жесткие требования, чем к бытовым: они должны быть переработаны до состояния нетоксичного отхода, а затем утилизированы, либо путем захоронения, либо другим способом.
Использование табачных отходов теоретически возможно для получения технически ценных продуктов, например, лимонной и яблочной кислот (для пищевой промышленности), никотина (для медицины), табачной смолы (для парфюмерии). Однако этот процесс дорогостоящий и вследствие этого малоприменимый [3].

Известно использование табачной пыли в качестве средств защиты сельскохозяйственных культур от вредителей.

Табачная пыль обладает выраженными инсектицидными свойствами и не представляет опасности для теплокровных и человека, что позволяет рассматривать использование табачной пыли в качестве инсектицида. При этом есть явные преимущества - кратность обработки может быть гораздо выше, а период ожидания гораздо короче, чем у химических препаратов.

Есть примеры использования табачной пыли для защиты растений на приусадебных участках, в личных подсобных хозяйствах.

Установлено, что однократная обработка инсектицидным водным экстрактом из табачной пыли способствует существенному (на 95\%) снижению численности персиковой тли на табаке и на $85-100 \%$ - обыкновенного паутинного клеща на огурцах. Период защитного действия для испытуемого экстракта из табачной пыли составляет 14 суток. Отмечено ростостимулирующее влияние экстракта на рост и развитие растений. Установлено отсутствие действующего вещества экстракта никотина через 3-е суток после обработки растений [4].

В лаборатории технологии производства табачных изделий ФГБНУ ВНИИТТИ были проведены исследования возможности использования отходов в виде табачной мелочи для изготовления новых видов табачных изделий - сосательного, нюхательного табаков и кальянных смесей.

Табачная мелочь, образующаяся на линии упаковки сигарет, представляет собой смесь мелких кусочков резаного табака хорошего качества без посторонних примесей. Однако, в связи с низкими технологическими свойствами, использование ее в сигаретах нецелесообразно и экономически не выгодно.

Обычный способ изготовления кальянных смесей и некурительных табаков предполагает использование листового табачного сырья. Для этого листья увлажняют, сортируют, измельчают и смешивают с заданными ингредиентами целевого продукта.

Нами был предложен способ усовершенствования технологии изготовления новых видов табачной продукции путем замены дорогостоящего листового табака на табачную мелочь, содержащую в своем составе смесь подобранных в различных соотношений сортотипов табака. 
В таблице 1 приведены результаты исследования химического состава табачной мелочи сигарет двух наименований. В качестве контроля был выбран листовой табак Берлей, выращенный на опытно-селекционном участке ФГБНУ ВНИИТТИ, в качестве контроля.

Анализ результатов, приведенных в таблице 1 , свидетельствует о том, что табачная мелочь не уступает по химическому составу контрольным образцам и может быть использована при изготовлении некурительных и кальянных табаков.

Следующий этап исследований - определение фракционного состава табачной мелочи. Для этого использовали прибор Jel-200 с набором сит разного диаметра. Результаты приведены в таблице 2.

Фракцию более 5 мм использовали при изготовлении опытных образцов кальянных смесей. Фракцию менее 5 мм - для изготовления опытных образцов некурительных табаков. В основу контрольных образцов был положен листовой табак Берлей.

Качество некурительной продукции определяли органолептически по 100-бальной системе на основе дегустационной оценки, разработанной в лаборатории технологии производства табачных изделий $[5,6,7]$. Результаты дегустационной оценки приведены в таблице 3. Следует отметить приятный аромат образцов нюхательного табака.

Таблица 1 .

Химический состав табачного сырья

Table 1.

Chemical composition of tobacco

\begin{tabular}{|l|c|c|c|c|}
\hline \multirow{2}{*}{\multicolumn{1}{|c|}{ Вариант Sample }} & \multicolumn{3}{|c|}{$\begin{array}{c}\text { Содержание компонентов химического состава (\%) } \\
\text { Composition of defined chemicals (\%) }\end{array}$} \\
\cline { 2 - 5 } & Никотин Nicotine & $\begin{array}{c}\text { Углеводы Carbo- } \\
\text { hydrates }\end{array}$ & Белки Proteins & Хлор Chlorine \\
\hline $\begin{array}{l}\text { Образец № 1 } \\
\text { Sample 1 }\end{array}$ & 1,2 & 7,3 & 7,9 & 0,17 \\
\hline $\begin{array}{l}\text { Образец № 2 } \\
\text { Sample 2 }\end{array}$ & 1,8 & 7,4 & 5,5 & 0,06 \\
\hline $\begin{array}{l}\text { Контроль (Берлей) } \\
\text { Reference sample (Burley) }\end{array}$ & 2,4 & 5,6 & 6,8 & 0,12 \\
\hline
\end{tabular}

Таблица 2.

Фракционный состав табачной мелочи

Table 2.

Fractional composition of tobacco scrap

\begin{tabular}{|c|c|c|c|}
\hline \multirow{2}{*}{$\begin{array}{c}\text { № oбразца (мешка) } \\
\text { Sample (blend) }\end{array}$} & \multicolumn{3}{|c|}{$\begin{array}{c}\text { Фракционный состав } \\
\text { Fractional composition }\end{array}$} \\
\cline { 2 - 4 } & $\geq 5 \mathrm{~mm}$ & $5 \div 1,0 \mathrm{~mm}$ & $\leq 1 \mathrm{~mm}$ \\
\hline 1 & 22,3 & 76,8 & 0,9 \\
\hline 2 & 21,7 & 77,9 & 0,4 \\
\hline 3 & 20,8 & 78,6 & 0,6 \\
\hline
\end{tabular}

Дегустационная оценка табачных изделий

Таблица 3.

Tasting of tobacco products

Table 3.

\begin{tabular}{|l|c|c|}
\hline \multicolumn{1}{c|}{$\begin{array}{c}\text { Наименование образца } \\
\text { Sample name }\end{array}$} & \multicolumn{2}{c|}{$\begin{array}{c}\text { Дегустационная оценка } \\
\text { (баллы) Tasting score (points) }\end{array}$} \\
\cline { 2 - 3 } & Контроль Control & Oпыт Experimental \\
\hline Нюхательный табак Snuff tobacco & 76,8 & 79,2 \\
\hline Сосательный табак Tobacco for sucking & 79,4 & 81,2 \\
\hline Смесь для кальяна Hookah blend & 80,6 & \\
\hline
\end{tabular}

Результаты, приведенные в таблице 3, позволяют сделать вывод, что образцы некурительных табаков, изготовленные из мелочи, собираемой на сигаретных машинах, не уступают по качеству образцам, изготовленным из листового табака, обладают богатым вкусом и приятным, ярко выраженным табачным ароматом. 


\section{Заключение}

Обобщая полученные результаты, можно сделать выводы:

- использование отходов сигаретного производства при изготовлении кальянных смесей и табачных изделий позволяет решить вопрос возврата в основное производство отходов, считавшихся невозвратными;

- продукция, изготовленная на основе табачной мелочи, позволяет получить продукт высокого качества, т. к. мелочь содержит в своем составе смесь табаков хорошего качества;

\section{ЛИТЕРАТУРА}

1 Ларькина Н.И. Шураева Г.П., Гнучих Е.В. Решение актуальных проблем табачной отрасли при ее научном обеспечении // Итоги и перспективы научных исследований. 2016. № 3. C. $110-126$.

2 Плотникова Т.В., Дон Т.А., Миргородская А.Г. Биологическая и экологическая эффективность использования отходов табачного производства в качества инсектицида // Современное состояние естественных и технических наук: матер. VI Междунар. науч.-практ. конф. (20.03.2012 г.). М.: «Спутник+», 2012. С. 127-130.

3 Плотникова Т.В., Миргородская А. Г. , Шураева Г.П., Дон Т.А. и др. Применение отходов табачного производства в качестве средств защиты сельскохозяйственный культур от вредителей // Труды Кубанского государственного аграрного университета. 2015. № 5(56). С. 153-158.

4 Жабенцова О.А., Шкидюк М.В., Бедрицкая О.К. Способы снижения токсичности кальянных смесей // Сборник Инновационные технологии в пищевой промышленности: наука, образование и производство. Международная научно-практическая конференция. 2013. C. 570-573.

5 Приходько Р.П., Моисеев И.В., Мойсяк М.Б., Моисеев Д.И. и др. Пути улучшения потребительских свойств кальянного табака // Сборник докладов V межведомственной научно-практической конференции «Товароведение и вопросы длительного хранения продовольственных товаров» 25-26 апреля 2013, ООО «Франтера». 2013. С. 156-159.

6 Rainey C.L., Conder P.A., Goodpasyer J.V. Chemical characterization of dissolvable tobacco products, promoted to reduce harm // Journal of Agricultural and Food Chemistry. 2011. V.59. P. 2745-2751.

7 Tobacco Dust. URL: http:// www.compostsoil.co/za/tobaccodust.html.
- имеет место значительное сокращение процесса производства за счет сокращения операции по очистке, увлажнению, сортировке и измельчению листьев табака;

- использование мелочи вместо дорогостоящего листового табака улучшает качество продукции за счет присутствия натурального табачного вкуса и аромата. Разница цены листового табака и отходов снижает себестоимость продукции на $90 \%$.

\section{REFERENCES}

1 Larkina N.I., Shuraeva G.P., Gnuchih E.V. Solving actual problems of tobacco industry. Itogi $i$ perspektivy nauchnykh issledovanii [Results and perspectives of researches] 2016, no. 3, pp. $110-$ 126. (in Russian)

2 Plotnikova T.V., Don T.A., Mirgorodskaya A.G. Biological and ecological efficiency of utilizing tobacco industrial wastes as insecticide. Sovramennoe sostoyanie estestvennykh i tekhnichekikh nauk [Modern situation in natural and technical sciences: materials of VI International conference 20.03.2012, Moscow] 2012, pp. 127-130. (in Russian)

3 Plotnikova T.V., Mirgorodskaya A.G., Shuraeva G.P., Don T.A. et al. Utilizing industrial tobacco wastes for protection agricultural plants against pests. Trudy Kubanskogo gosudarstvennogo agrarnogo universiteta [Works of Kuban State Agricultural University] 2015, no. 5(56), pp. 153-158. (in Russian)

4 Zhabencova O.A., Shkiduk M.V., Bedritskaya O.K. Methods for decreasing toxicity of hookah blends. Sborrnik Innovatsionnye tekhnologii v pishchevoi promyshlennosti: nauka, obrazivanie i proizvodstvo [Innovative technologies in food industry: science, education and industry. International scientific conference] 2013, pp. 570-573. (in Russian)

5 Prihod'ko R.P., Moiseev I.V., Moisiak M.B., Moiseev D.I. et al. Methods for improving consumers' properties of hookah tobacco. Tovarovadanie i voprosy dlitel'nogo khraneniya prodovol'stvennykh tovarov [Reports of V interdepartmental conference "Commodities research and prolonged keeping of food goods" 25-26 April 2013 LLC "Frantera"] 2013, pp. 156-159. (in Russian)

6Rainey C.L., Conder P.A., Goodpasyer J.V. Chemical characterization of dtssolvable tobacco products, promoted to reduce harm. Journal ot Agricultural and Food Chemistry, 2011, vol. 59, pp. 2745-2751.

7 Tobacco Dust. Available at: http://www.compostsoil.co/za/tobaccodust.html. 


\section{СВЕДЕНИЯ ОБ АВТОРАХ}

Тамара А. Дон научн. сотр., лаборатория технологии производства табачных изделий, Всероссийский научно-исследовательский институт табака, махорки и табачных изделий, ул. Московская, 42, г. Краснодар, 350072, Россия, tabak.technolog@ rambler.ru

Алла Г. Миргородская к. т. н, зав. лаб., лаборатория технологии производства табачных изделий, Всероссийский научно-исследовательский институт табака, махорки и табачных изделий, ул. Московская, 42, г. Краснодар, 350072, Россия, mirgorodskaya-alla@ mail.ru Ольга К. Бедрицкая ст. научн. сотр., лаборатория технологии производства табачных изделий, Всероссийский научно-исследовательский институт табака, махорки и табачных изделий, ул. Московская, 42, г. Краснодар, 350072, Россия, tabak.technolog@ @rambler.ru

\section{КРИТЕРИЙ АВТОРСТВА}

Тамара А. Дон обзор литературных источников по исследуемой проблеме

Алла Г. Миргородская консультация в ходе исследования Ольга К. Бедрицкая написалА рукопись, корректировала её до подачи в редакцию и несёт ответственность за плагиат

\section{КОНФЛИКТ ИНТЕРЕСОВ}

Авторы заявляют об отсутствии конфликта интересов.

ПОСТУПИЛА 02.08.2016

ПРИНЯТА В ПЕЧАТЬ 22.08.2016

\section{INFORMATION ABOUT AUTHORS}

Tamara A. Don reseacher, laboratory of technologies for manufacturing tobacco products All-Russian research institute of tobacco, makhorka and tobacco products, Moskovskaya St., 42, Krasnodar, 350072, Russia

Alla G. Mirgorodskaya candidate of technical sciences, head of laboratory, laboratory of technologies for manufacturing tobacco products All-Russian research institute of tobacco, makhorka and tobacco products, Moskovskaya St., 42, Krasnodar, 350072, Russia

Olga K. Bedritskaya senior researcher, laboratory of technologies for manufacturing tobacco products All-Russian research institute of tobacco, makhorka and tobacco products, Moskovskaya St., 42, Krasnodar, 350072, Russia

\section{CONTRIBUTION}

Tamara A. Don review of the literature on an investigated problem

Alla G. Mirgorodskaya consultation during the study

Olga K. Bedritskaya wrote the manuscript, correct it before filing in editing and is responsible for plagiarism

\section{CONFLICT OF INTEREST}

The authors declare no conflict of interest.

RECEIVED 8.2.2016

ACCEPTED 8.22.2016 